\title{
Guanylin and $E$. coli Heat-Stable Enterotoxin Induce Chloride Secretion through Direct Interaction with Basolateral Compartment of Rat and Human Colonic Cells
}

\author{
FABIO ALBANO, GIULIO DE MARCO, ROBERTO BERNI CANANI, PIA CIRILLO, \\ VITTORIA BUCCIGROSSI, RALPH A. GIANNELLA, AND ALFREDO GUARINO
}

Department of Pediatrics [F.A., G.D.M., R.B.C., P.C., V.B., A.G.], University "Federico II," 80131

Naples, Italy, Division of Digestive Diseases [R.A.G.], University of Cincinnati College of Medicine,

Veterans Administration Medical Center, Cincinnati, Ohio 45267

\begin{abstract}
ABS
We previously detected specific binding activity of Esche-
richia coli heat-stable enterotoxin (ST), the guanylin exogenous
ligand, in rat colonic basolateral membranes. Because guanylin
circulates in the bloodstream, we tested the hypothesis that it
modulates intestinal ion transport by acting on the serosal side of
intestinal cells. The effects of the mucosal and serosal addition of
ST and guanylin on ion transport were investigated in the rat
proximal colon and in Caco-2 cells in Ussing chambers, by
monitoring short-circuit current (Isc). cGMP concentration was
measured in Caco-2 cells by RIA. Mucosal ST addition induced
an increase in Isc in rat proximal colon consistent with anion
secretion. Serosal addition induced the same effects but to a
lesser extent. The electrical effects observed in Caco-2 cells
paralleled those observed in rat proximal colon. A pattern similar
to the electrical response was observed with cGMP concentra-
tion. Guanylin addition to either side of Caco-2 cells induced the
same effects as ST, although to a lesser extent. In all conditions,
\end{abstract}
ST elaborated by Escherichia coli and other bacteria are structurally related peptides that activate the transmembrane protein GC-C, located on the intestinal BBM of small and large intestinal enterocytes (1-3). ST binding to GC-C results in the generation of cGMP (4,5), which activates type-II cGMPdependent protein kinase, leading to the phosphorylation of the CFTR and eventually results in chloride and bicarbonate secretion (6-8). The clinical manifestation of ST effects is diarrhea. This is of the secretory type and is particularly severe in younger infants (9).

Received May 20, 2004; accepted November 24, 2004.

Correspondence: Alfredo Guarino, M.D., Department of Pediatrics, University "Federico II,” Via S. Pansini 5, 80131 Naples, Italy; e-mail: alfguari@unina.it

Supported by a grant (number 50D28) from the Istituto Superiore di Sanità, 4th AIDS Research Project.

DOI: 10.1203/01.PDR.0000163380.96434.B9 the electrical effect disappeared in the absence of chloride. ST directly interacts with basolateral receptors in the large intestine inducing chloride secretion through an increase of cGMP. However, the serosal effects are less pronounced compared with those observed with mucosal addition. Guanylin shows the same pattern, suggesting that it plays a role in the regulation of ion transport in the colon, but the relative importance of serosally mediated secretion remains to be determined. (Pediatr Res 58: 159-163, 2005)

$\quad$ Abbreviations
BBM, brush border membrane
BLM, basolateral membranes
CFTR, cystic fibrosis transmembrane regulator
GC-C, guanylyl cyclase C
Isc, short-circuit current
ST, heat-stable enterotoxin

Because the endogenous ligands of GC-C receptor, guanylin, and uroguanylin $(10,11)$ activate the same pathway and cause an increase in Isc in intestinal epithelial cells, it has been suggested that they play a role in regulating intestinal fluid secretion. In most mammalian species, both peptides are produced predominantly in the intestine, although uroguanylin is also expressed in the kidney (12-14). Proguanylin and prouroguanylin are secreted into the intestinal lumen but they are also detected in the bloodstream as $11-\mathrm{kD}$ prohormones and are each cleaved to the active 15 amino acid carboxy termini that bind GC-C (15-17). Circulating uroguanylin induces natriuresis, kaliuresis, and diuresis in isolated perfused rat kidney. It has been suggested that uroguanylin represents a gutto-kidney signaling hormone that, upon ingestion of high-salt meals, causes natriuresis in anticipation of increased intestinal salt absorption $(18,19)$. However, guanylin and uroguanylin may have other physiologic roles $(20,21)$, including the acti- 
vation of a cGMP signal transduction pathway that may take part in the regulation of the turnover of epithelial cells by continuous replenishment of the epithelial cells $(22,23)$.

ST is more potent than either guanylin or uroguanylin in stimulating intestinal secretion as judged by the effects on Isc of intestinal epithelium mounted in Ussing chambers. Because of these properties, ST is commonly used to study the GC-Cdependent secretory system in the rat and human intestine (24-28). Receptors for ST are located in the BBM. The addition of ST to the mucosal side of human colonic T84 cell stimulated active chloride secretion and the production of cGMP (26). Furthermore, ST showed similar binding kinetics in human intestinal and in colon-derived Caco-2 cells. Receptors for ST have been detected in the rat colon (28).

We have previously shown that ST binds specifically to highly purified BLM from rat colon (29). Because the endogenous ligands for GC-C, guanylin, and uroguanylin circulate in the blood, we hypothesized that guanylin or ST might be active when applied to the serosal surface of the colon.

To test this, we performed experiments with addition of ST to either side of rat colon mounted in Ussing chambers. We also used cell monolayers from human colon carcinoma cell line Caco-2. The experiments were repeated using guanylin to test our original hypothesis.

\section{MATERIALS AND METHODS}

Animals. Sprague-Dawley rats weighing 200-250 g were used. Animals were fed Purina rat chow and fasted $6 \mathrm{~h}$ before experiments but were allowed free access to water.

Cell growth and culture. The human intestinal epithelial cell line Caco-2 has been established from a moderately well-differentiated colon carcinoma. Caco-2 cells were grown in Dulbecco's modified Eagle minimum essential medium with high glucose concentration $(4.5 \mathrm{~g} / \mathrm{L})$ at $37^{\circ} \mathrm{C}$ in $5 \% \mathrm{CO}_{2}$ atmosphere as previously described (30). The medium was supplemented with $10 \%$ FCS, $1 \%$ nonessential amino acids, penicillin $(50$ milliunits $/ \mathrm{mL})$, and streptomycin $(50 \mu \mathrm{g} / \mathrm{mL})$. The medium was changed daily.

Cells were grown on uncoated, nontransparent polycarbonate Transwell filters $\left(0.4 \mu \mathrm{m}\right.$ pore size, $24.5 \mathrm{~mm}$ diameter; $2 \times 10^{6}$ cells were plated per filter). Cells were between the 50th and 70th passages and were used for intestinal transport studies $15 \mathrm{~d}$ after seeding when they formed a single layer of confluent cells connected by tight junctions and produce transepithelial electrical resistance (TEER) typical of polarized epithelial cells.

Intestinal ion transport studies in animals. Rats were killed by cervical dislocation and a $5-\mathrm{cm}$ segment of proximal colon, $1-2 \mathrm{~cm}$ distal to the cecal-colonic junction, was rapidly removed and rinsed with ice-cold Ringer solution with the following composition: $53 \mathrm{mM} \mathrm{NaCl}, 5 \mathrm{mM} \mathrm{KCl}, 30.5 \mathrm{mM}$ $\mathrm{Na}_{2} \mathrm{SO}_{4}, 25 \mathrm{mM}$ mannitol, $1.69 \mathrm{mM} \mathrm{Na} \mathrm{HPO}_{4}, 0.3 \mathrm{mM} \mathrm{NaH} \mathrm{PO}_{4}, 1.25 \mathrm{mM}$ $\mathrm{CaCl}_{2}, 1.1 \mathrm{mM} \mathrm{MaCl}$, and $25 \mathrm{mM} \mathrm{NaHCO}$. Four paired fragments of unstripped colonic mucosa were mounted in Ussing chambers. In each experiment, one fragment served as control of baseline electrical parameters.

The solution was maintained at $37^{\circ} \mathrm{C}$ with water-jacketed reservoirs connected to a thermostated circulating pump and constantly gassed with $95 \%$ $\mathrm{O}_{2} / 5 \% \mathrm{CO}_{2}$. Transepithelial potential difference (PD), Isc, and tissue ionic conductance $(\mathrm{G})$ were measured as previously described (30). Isc is expressed as $\mu \mathrm{A} / \mathrm{cm}^{2}, \mathrm{G}$ as $\mathrm{mS} / \mathrm{cm}^{2}$, and PD as $\mathrm{mV}$. Electrical parameters were recorded before and at various times after the addition of ST to the mucosal or the serosal side.

All animal experimentation described was approved by the Institutional Animal Care and Use Committee.

Intestinal ion transport studies in Caco-2 cells. Each filter was mounted as a flat sheet between the mucosal and serosal compartment of Ussing chambers. Each compartment contained $10 \mathrm{~mL}$ of Ringer's solution with the following composition: $114 \mathrm{mM} \mathrm{NaCl}, 5 \mathrm{mM} \mathrm{KCl}, 1.65 \mathrm{mM} \mathrm{Na} \mathrm{HPO}_{4}, 0.3 \mathrm{mM}$ $\mathrm{NaH}_{2} \mathrm{PO}_{4}, 1.25 \mathrm{mM} \mathrm{CaCl}_{2}, 1.1 \mathrm{mM} \mathrm{MgCl} 2,25.0 \mathrm{mM} \mathrm{NaHCO}_{3}$, and $10.0 \mathrm{mM}$ glucose.

ST or guanylin were added to either the mucosal or serosal side of the filter.

To see whether the electrical effect was consistent with anion secretion rather than cation absorption, experiments were performed, both in cells and rats, in $\mathrm{Cl}^{-}$-free Ringer's solution in which $\mathrm{SO}_{4}{ }^{-}$replaced $\mathrm{Cl}^{-}$ions at equimolar concentration.

Cell and rat colonic fragment viability was assessed at the end of each experiment in paired controls by measuring the electrical response to serosal addition of $5 \mathrm{mmol}$ of theophylline. An Isc increase of at least 3-fold compared with the preaddition value was considered proof of cell viability.

Determination of cGMP concentrations. After completing the Ussing chamber studies, the filter was rapidly removed from each chamber, transferred to ice-cold 5\% trichloroacetic acid (TCA) and homogenized. The homogenate was centrifuged at $2000 \mathrm{~g}$ for $3 \mathrm{~min}$ at $4^{\circ} \mathrm{C}$, and the supernatant was collected and evaporated to dryness under vacuum (Speed VAC 110, Savant Instruments, Farmingdale, NY). The dried sample was redissolved in $0.5 \mathrm{M}$ acetate buffer, $\mathrm{pH} 5.8$ with $0.01 \%$ sodium azide, and cGMP concentration was measured using a RIA commercial kit (cGMP ${ }^{125}$ I assay system; Amersham Pharmacia Biotech UK, Ltd., Little Chalfont, Buckinghamshire, UK), according to the manufacturer's instructions. Results were calculated as picomoles of cGMP per square centimeter and expressed as fold increase over basal level.

ELISA assay for ST. The presence of ST in the fluid bathing the mucosal surface of epithelium after ST serosal addition was tested by an ELISA test with MAb raised against pure 18-amino acid E. coli ST as described elsewhere (31).

Chemicals. All chemicals, including ST and guanylin, were of reagent grade and were obtained from Sigma-Aldrich Italy (Milan, Italy); culture media were from Invitrogen (Milan, Italy). Transwell filters were from Costar (Costar Italia, Milan, Italy).

Statistics. Each experiment was run in duplicate and repeated at least four times. Results are expressed as means $\pm \mathrm{SD}$. Two-tailed, unpaired $t$ test was applied to evaluate statistical significance. A value of $p<0.05$ was considered statistically significant.

\section{RESULTS}

Electrical effects of ST in rat colon. The addition of ST $\left(10^{-6} \mathrm{M}\right)$ to the mucosal side of rat colon induced a prompt increase of Isc that reached a maximum 2 min after addition and then slowly decreased toward baseline (Fig. 1). Isc increase was entirely related to a modification of PD inasmuch as no variations of $\mathrm{G}$ were observed.

The addition of ST to the serosal side also induced a rise of Isc that was very similar to that observed with mucosal addition but with a reduced Isc peak (Fig. 1). Both the mucosal and

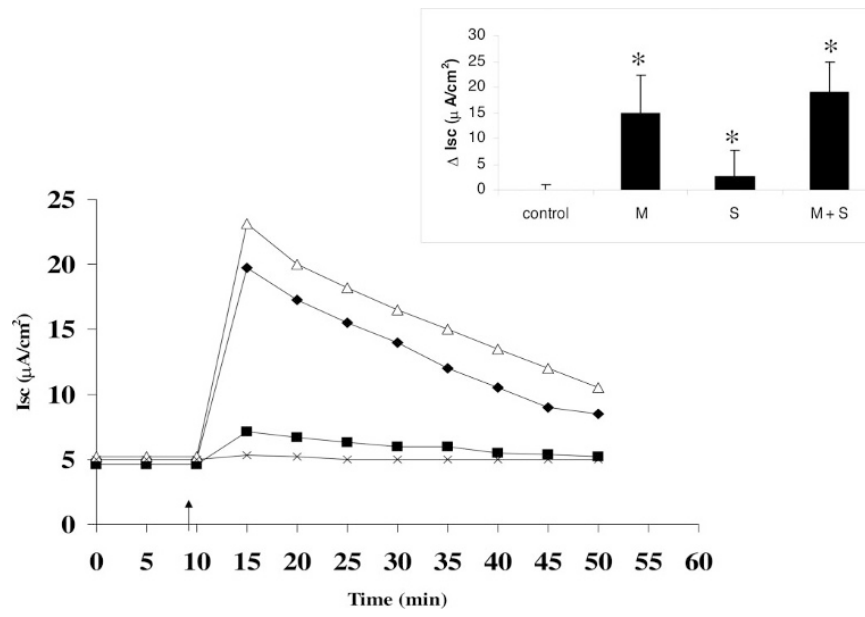

Figure 1. Time course of the effect of the addition of ST to the mucosal ( $\bullet$ ) or serosal ( $\square$ ) compartments on Isc of rat colon mounted in an Ussing chamber. The addition of ST $\left(10^{-6} \mathrm{M}\right)$ to each side of colonic specimens induced a rapid increase in Isc. The simultaneous addition of ST to the mucosal and serosal $(\Delta)$ compartments of rat proximal colon in a concentration capable of inducing a maximal response induced no further increase in Isc. No increase in Isc was observed, in the absence of $\mathrm{Cl}^{-}$, upon either the mucosal $(\times)$or serosal (data not shown) addition of ST. Mean and SD of the peak effect of ST in at least four experiments is shown in the inset $\left({ }^{*} p<0.05 v s\right.$ controls). 
serosal effects were dose dependent, and on both sides the maximal effect was observed with ST concentration of $10^{-6} \mathrm{M}$ (data not shown). After determining the dose-response, ST was simultaneously added to both the mucosal and serosal compartments in the concentration capable of eliciting the maximal effect, and it did not correspond to the sum of those observed with ST addition to either side. A further Isc increase compared with the mucosal effect was consistently observed (Fig. 1). However, this increase did not reach the level of statistical significance.

All electrical modifications were inhibited in chloride-free buffer (Fig. 1).

Electrical effects of ST in Caco-2 cells. The addition of ST $\left(10^{-6} \mathrm{M}\right)$ to the mucosal side of Caco-2 cells induced an electrical response that was similar to that observed in rat proximal colon (Fig. 2). Half maximal effect was observed at a concentration of $5 \times 10^{-7}$ (Fig. 3A). The Isc response was maximal at a ST concentration of $10^{-6} \mathrm{M}$. Higher concentrations of ST did not result in any further increase in Isc, indicating a saturation pattern of the effect (Fig. 3A).

The concentration of ST stimulating a maximal response in Isc was the same for both mucosal and serosal addition (Fig. $3 A$ ). The addition of ST to the serosal side induced a rise in Isc that was very similar to that observed with mucosal addition with regard to the time course. However, the potency of maximal electrical effect was approximately $25 \%$ compared with that observed in response to mucosal addition (Fig. 2). Also in this model, the simultaneous addition of ST to both the mucosal and serosal compartments induced an Isc peak response that was not significantly increased compared with that observed with mucosal addition. All electrical modifications were inhibited in chloride-free buffer (Fig. 2) .

Electrical effects of Guanylin in Caco-2 cells. The same experiments performed with ST were repeated using guanylin. The addition of guanylin $\left(10^{-6} \mathrm{M}\right)$ to the mucosal side of

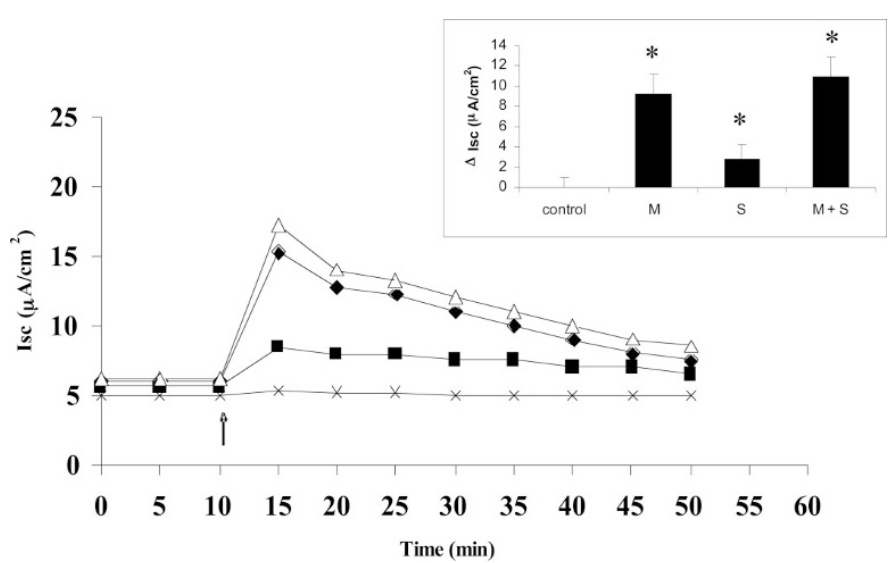

Figure 2. Time course of the effect of the addition of ST to the mucosal $(\bullet)$ or serosal ( $\square$ ) compartments on Isc of Caco-2 cells mounted in an Ussing chamber. The addition of ST $\left(10^{-6} \mathrm{M}\right.$ ) (arrow) to each side of Caco- 2 cells induced an increase in Isc that was similar to that observed in the rat model. The simultaneous addition of ST to the mucosal and serosal $(\Delta)$ compartments induced no further increase in Isc. No increase in Isc was observed, in the absence of $\mathrm{Cl}^{-}$, upon either the mucosal $(\times)$or serosal (data not shown) addition of ST. Mean and SD of the peak effect of ST in at least four experiments is shown in the inset ( ${ }^{*} p<0.05 v s$ controls).
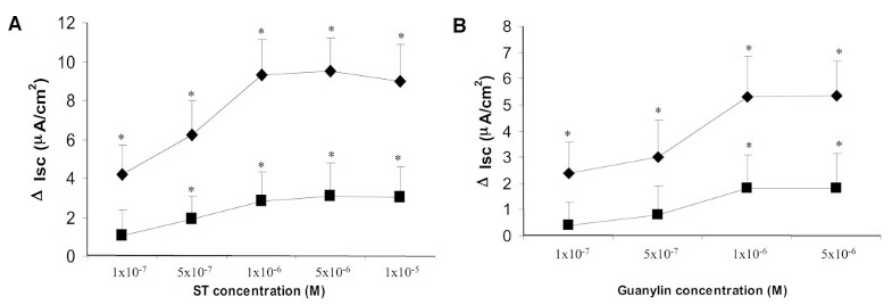

Figure 3. (A) Effect of increasing concentrations of ST on Isc of Caco-2 cells. The addition of ST to the mucosal $(\bullet)$ or serosal $(\square)$ side resulted in a dose-dependent increase of Isc. There were four experiments per dose. *Statistically significant $v s$ controls $(p<0.05)$. (B) Effect of increasing concentrations of guanylin on Isc of Caco-2 cells. The addition of ST to the mucosal $(\downarrow)$ or serosal $(\square)$ side resulted in a dose-dependent increase of Isc. There were four experiments per dose. *Statistically significant $v s$ controls $(p<$ $0.05)$.

Caco-2 cells induced an increase of Isc (data not shown) closely resembling that observed with ST. However, the potency of guanylin was approximately $50 \%$ of that observed with ST at equimolar concentrations.

Guanylin addition to the serosal side also induced a rise in Isc, whose magnitude was approximately $30 \%$ of mucosal effect. The concentration of guanylin stimulating the maximal response in Isc was the same for both mucosal and serosal addition and corresponded to $10^{-6} \mathrm{M}$ (Fig. $3 \mathrm{~B}$ ). When guanylin at a concentration of $10^{-6} \mathrm{M}$ was simultaneously added to both the mucosal and serosal compartments, the magnitude of the Isc response was greater than that observed with addition to the mucosal side. However, the difference did not reach statistical significance. Therefore, all the features of guanylininduced secretion were similar to that of ST, although the potency of the secretory effect was reduced.

Effects of mucosal or serosal addition of ST or guanylin on cGMP concentration. As shown in Figure 4, ST and guanylin stimulated the production of cGMP in a dose-dependent manner in Caco-2 cells. Maximal ST-stimulated cGMP production was observed with an ST concentration of $10^{-6} \mathrm{M}$ added to the mucosal compartment, resulting in a 14-fold increase in cGMP levels. Comparatively, the maximal cGMP increase upon ST serosal addition was 9-fold (Fig. 4A). When guanylin was added, the maximal increase of cGMP was reduced compared with the effect obtained with E. coli ST (Fig. 4).
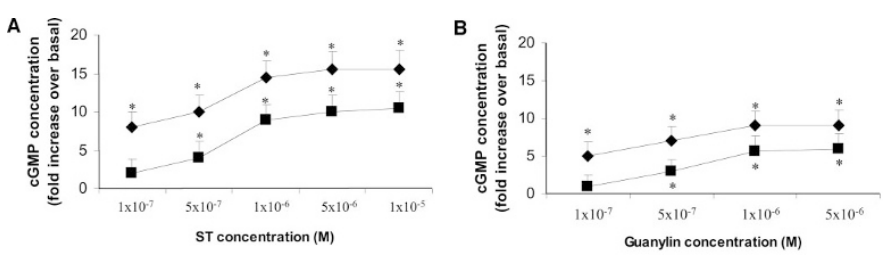

Figure 4. (A) Effect on cGMP concentration of the addition of ST to the mucosal $(\diamond)$ or serosal $(\square)$ side of Caco-2 cells monolayers. ST induced an increase of cGMP concentration in a dose-dependent manner. The maximal increase was observed with $10^{-6} \mathrm{M}$ of ST added to the mucosal or serosal compartment. There were four experiments per dose. *Statistically significant $v s$ controls $(p<0.05)$. (B) The effects of guanylin showed the same pattern observed with ST. The magnitude of toxin effect was higher than that of its endogenous ligand. There were four experiments per dose. *Statistically significant $v s$ controls $(p<0.05)$. 
The simultaneous addition of ST or guanylin in a concentration of $10^{-6} \mathrm{M}$ to both sides of the Caco-2 cells induced a slight further increase in cGMP, not statistically different from that observed upon mucosal addition (Fig. 5).

Therefore, the mucosal or serosal addition of ST or guanylin was associated with an increase of cGMP concentration that showed a dose-response pattern that was similar to that observed in Ussing chamber experiments.

ELISA Assay for ST. The fluid bathing the mucosal surface of epithelium mounted in Ussing chambers was collected after ST addition on the serosal side. It produced an ELISA negative ST, indicating that there was no transepithelial flux of the toxin (data not shown).

\section{DISCUSSION}

Our data show that ST is active when added to the serosal side of rat colon or Caco-2 cells and that its effect is similar to that induced by mucosal addition, although less potent. We used the rat proximal colon to perform our initial experiments because we had previously detected ${ }^{125} \mathrm{I}$-ST binding activity in basolateral membranes purified from this intestinal segment (29). The time and kinetic features of the electrical effects observed in the present work were similar to those detected with mucosal ST addition and consistent with anion secretion. The complete loss of the effect in the absence of chloride supports this interpretation.

ST effects and its mechanisms were further investigated in Caco-2 cells, a well-established model to study intestinal secretion. The electrical response was similar to that observed in the animal model, suggesting that serosally applied ST works by a similar pathway compared with that stimulated by apical addition. We also investigated its mechanisms and comparatively examined the effects of mucosal and serosal ST addition. The dose of ST capable of inducing the maximal increase in Isc on each side was identical. However, when maximal concentrations of ST were simultaneously added to the apical and basolateral compartments, the observed increase in Isc was not different from that observed with ST mucosal addition alone. This indicates that the pathway of ST is the same, independent of the route of ST access to the enterocyte. This is strongly

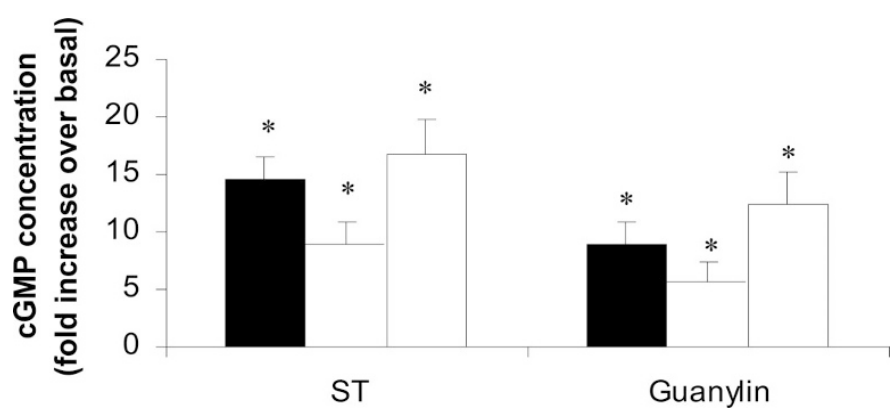

Figure 5. Effects on cGMP concentration of the addition of ST (left side) and guanylin (right side) to the mucosal ( $\square$ ) and serosal ( $\square$ ) side and to both sides (圆) of Caco-2 cell monolayers. The simultaneous addition of ST or guanylin at concentration of $10^{-6} \mathrm{M}$ to both sides of the Caco- 2 cells induced a further increase in cGMP concentration that did not reach the level of statistical significance compared with that observed upon mucosal addition. *Statistically significant $v s$ basal $(p<0.05)$. supported by a cGMP determination that showed a pattern identical to electrical data. Together with our data on the specific binding activity in BLM of rat proximal colon (29), this suggests that the same secretory pathway involved in mucosal ST response is activated by a basolateral stimulus. However, the magnitude of both the electrical response and the increase in cGMP upon serosal addition were reduced compared with that induced by mucosal addition. This is consistent with our finding that the specific binding in BBM of rat proximal colon was higher than in BLM, suggesting a decreased receptor density in the latter (29). The similarity in the dose-response effect to mucosal or serosal ST addition does not fit with this interpretation. However, a broad range of ST concentrations was used and it is possible that minor kinetic differences, such as a different response with double ST concentrations, were not identified. Alternatively, because the maximal ST concentration was the same on either side but the effect was different, the possibility of a different receptoreffector coupling in the BLM may explain the observed results.

Our finding of a response to serosal ST addition differs from that reported by others $(27,32-34)$. We have performed experiments to look for ST in the fluid bathing the mucosal surface of epithelium, after serosal ST addition. A transepithelial serosa-to-mucosa ST flux might have explained the observed results. We did not find any evidence of transepithelial flux of ST. We cannot explain why our data differ from that published by others other than the fact different cells and animal species were used.

Guanylin induced the same effects of ST, although its potency was reduced. A similar finding of a reduced secretion induced by a mucosal guanylin addition compared with ST has been reported previously (34). We observed the same difference in potency between the endogenous and exogenous GC-C ligands with the serosal application. Overall, our data therefore support the existence of a ST/guanylin-dependent activation pathway via the serosal route. The two ST-like endogenous ligands produced in the intestine, guanylin and uroguanylin, are released into the blood and may exert their effects on the serosal side of polarized enterocytes. Guanylin and uroguanylin are, in fact, secreted into the intestinal lumen as well as into the bloodstream in response to sodium chloride administration and may regulate ion and water transport in the intestine and kidney by luminocrine and endocrine actions (12-14).

An active role of the enterocyte in ion transport has been hypothesized (35). We have reported that the enterocyte responds to an enterotoxin-induced secretion through the activation of constitutive nitric oxide synthase functioning as a breaking force of ion secretion. The data in this article add to the concept that enterocytes play a major role in regulating ion transport. Guanylin and uroguanylin may regulate intestinal electrolyte homeostasis by acting on the serosal surface of the colonic mucosa as well as on the apical membrane of small intestinal enterocytes.

ST effector GC-C shows an age-related pattern and peak at the newborn stage (36). It may therefore be hypothesized that the ST/guanylin-receptor system could help prevent excessive growth and proliferation of potentially pathogenic microorgan- 
isms through their washing out at an age in which the susceptibility to intestinal infection is highest.

Children with cystic fibrosis (CF) lack the CFTR anion channel and in these patients the colon is unresponsive to ST (37). The CF newborn infant has a high risk of intestinal obstruction due to impaction of meconium. We have previously shown that ST receptors have an age-related pattern, peaking in the first $3 \mathrm{~d}$ of life (38). This suggests that guanylin may have the additional specific function of promoting chloride secretion to allow meconium output.

In conclusion, the results of this work show that 1) ST and guanylin induce chloride secretion when added to the serosal side of intestinal epithelium; 2) the effect has similar kinetic features compared with mucosal addition, but is less potent; 3) the effect is not additive to that observed with mucosal addition, although a further minor increase in either Isc and cGMP is consistently observed; and 4) guanylin is less potent than ST as a secretagogue. Overall, the results of this work raise the hypothesis that the colon is a target organ for both the paracrine and the endocrine effects of guanylin, acting on either side of the epithelium to reduce absorption and induce net $\mathrm{Cl}^{-}$ secretion.

\section{REFERENCES}

1. de Sauvage FJ, Camerato TR, Goeddel DV 1991 Primary structure and functional expression of the human receptor for Escherichia coli heat-stable enterotoxin. J Biol Chem 266:17912-17918

2. Schulz S, Green CK, Yuen PS, Garbers DL 1990 Guanylyl cyclase is a heat-stable enterotoxin receptor. Cell 63:941-948

3. Cohen MB, Giannella RA 1995 Enterotoxigenic E. coli. In: Blaser MJ, Smith PD, Ravdin JI, Greenberg HB (eds) Infections of the Gastrointestinal Tract. New York, Raven Press, pp 691-707

4. Field M, Graf LH Jr, Laird WJ, Smith PL 1978 Heat-stable enterotoxin of Escherichia coli: in vitro effects on guanylate cyclase activity, cyclic GMP concentration, and ion transport in small intestine. Proc Natl Acad Sci U S A 75:2800-2804

5. Rao MC, Guandalini S, Smith PL, Field M 1980 Mode of action of heat-stable Escherichia coli enterotoxin. Tissue and subcellular specificities and role of cyclic GMP. Biochim Biophys Acta 632:35-46

6. Vaandrager AB, Bot AG, de Jonge HR 1997 Guanosine 3',5'-cyclic monophosphatedependent protein kinase II mediates heat-stable enterotoxin-provoked chloride secretion in rat intestine. Gastroenterology 112:437-443

7. Vaandrager AB, Bot AG, Ruth P, Pfeifer A, Hofmann F, de Jonge HR 2000 Differential role of cyclic GMP-dependent protein kinase II in ion transport in murine small intestine and colon. Gastroenterology 118:108-114

8. Kunzelmann K, Kiser GL, Schreiber R, Riordan JR 1997 Inhibition of epithelial Na+ currents by intracellular domains of the cystic fibrosis transmembrane conductance regulator. FEBS Lett 400:341-344

9. Guarino A, Alessio M, Tarallo L, Fontana M, Iacono G, Gobio Casali L, Guandalini S 1989 Heat stable enterotoxin produced by Escherichia coli in acute diarrhoea. Arch Dis Child 64:808-813

10. Currie MG, Fox KF, Kato J, Moore RJ, Hamra FK, Duffin KL, Smith CE 1992 Guanylin: an endogenous activator of intestinal guanylate cyclase. Proc Natl Acad Sci U S A 89:947-951

11. Hamra FK, Forte LR, Eber SL, Pidhorodeckyj NV, Krause WJ, Freeman RH, Chin DT, Tompkins JA, Fok KF, Smith CE 1993 Uroguanylin: structure and activity of a second endogenous peptide that stimulates intestinal guanylate cyclase. Proc Natl Acad Sci U S A 90:10464-10468

12. Whitaker TL, Witte DP, Scott MC, Cohen MB 1997 Uroguanylin and guanylin: distinct but overlapping patterns of messenger RNA expression in mouse intestine. Gastroenterology 113:1000-1006
13. Cohen MB, Witte DP, Hawkins JA, Currie MG 1995 Immunohistochemical localization of guanylin in the rat small intestine and colon. Biochem Biophys Res Commun 209:803-808

14. Fan X, Hamra FK, Freeman RH, Eber SL Krause WJ, Lim RW, Pace VM, Currie MG, Forte LR 1996 Uroguanylin: cloning of preprouroguanylin cDNA, mRNA expression in the intestine and heart and isolation of uroguanylin and prouroguanylin from plasma. Biochem Biophys Res Commun 219:457-462

15. Hamra FK, Fan X, Krause WJ, Freeman RH, Chin DT, Smith CE, Currie MG, Forte LR 1996 Prouroguanylin and Proguanylin: purification from colon, structure, and modulation of bioactivity by proteases. Endocrinology 137:257-265

16. de Sauvage FJ, Keshav S, Kuang WJ, Gillett N, Henzel W, Goeddel DV 1992 Precursor structure, expression, and tissue distribution of human guanylin. Proc Natl Acad Sci U S A 89:9089-9093

17. Schultz S, Chrisman TD, Garbers DL 1992 Cloning and expression of guanylin. Its existence in various mammalian tissues. J Biol Chem 267:16019-16021

18. Fonteles MC, Greenberg RN, Monteiro HS, Currie MG, Forte LR 1998 Natriuretic and kaliuretic activities of guanylin and uroguanylin in the isolated perfused rat kidney. Am J Physiol 275:F191-F197

19. Ohbayashi H, Yamaki K, Suzuki R, Takagi K 1998 Effects of uroguanylin and guanylin against antigen-induced bronchoconstriction and airway microvascular leakage in sensitized guinea-pigs. Life Sci 62:1833-1844

20. Zhang ZH, Jow F, Numann R, Hinson J 1998 The airway-epithelium: a novel site of action by guanylin. Biochem Biophys Res Commun 244:50-56

21. Cohen MB, Hawkins JA, Witte DP 1998 Guanylin mRNA expression in human intestine and colorectal adenocarcinoma. Lab Invest 78:101-108

22. Shailubhai K, Yu HH, Karunanandaa K, Wang JY, Eber SL, Wang Y, Joo NS, Kim HD, Miedema BW, Abbas SZ, Boddupalli SS, Currie MG, Forte LR 2000 Uroguanylin treatment suppresses polyp formation in the $\mathrm{APC}^{\mathrm{min} /+}$ mouse and induces apoptosis in human colon adenocarcinoma cells via cyclic GMP. Cancer Res 60:5151-5157

23. Wang Y, Eber SL, Rowland LM, Forte LR 2000 Uroguanylin induces apoptosis in human colon carcinoma cells via a cGMP-dependent mechanism. FASEB J 14:A360

24. Giannella RA, Luttrell M, Thompson MR 1983 Binding of Escherichia coli heatstable enterotoxin to receptors on rat intestinal cells. Am J Physiol 245:G492-G498

25. Guarino A, Cohen MB, Overmann G, Thompson MR, Giannella RA 1987 Binding of E. coli heat-stable enterotoxin to rat intestinal brush borders and to basolateral membranes. Dig Dis Sci 32:1017-1026

26. Guarino A, Cohen M, Thompson M, Dharmsathaphorn K, Giannella RA 1987 T84 cell receptor binding and guanyl cyclase activation by Escherichia coli heat-stable enterotoxin. Am J Physiol 253:G775-G780

27. Huott PA, Liu W, McRoberts JA, Giannella RA, Dharmsathaphorn K 1988 Mechanism of action of Escherichia coli heat-stable enterotoxin in a human colonic cell line. J Clin Invest 82:514-523

28. Mezoff AG, Giannella RA, Eade MN, Cohen MB 1992 Escherichia coli enterotoxin (STa) binds to receptors, stimulates guanyl cyclase, and impairs absorption in rat colon. Gastroenterology 102:816-822

29. Albano F, Brasitus T, Mann EA, Guarino A, Giannella RA 2001 Colonocyte basolateral membranes contain Escherichia coli heat-stable enterotoxin receptors. Biochem Biophys Res Comm 284:331-334

30. Guarino A, Canani RB, Casola A, Pozio E, Russo R, Bruzzese E, Fontana M, Rubino A 1995 Human intestinal cryptosporidiosis: secretory diarrhea and enterotoxic activity in Caco-2 cells. J Infect Dis 171:976-983

31. Thompson MR, Brandwein H, LaBine-Racke M, Giannella RA 1984 Simple and reliable enzyme-linked immunosorbent assay with monoclonal antibodies for detection of Escherichia coli heat stable enterotoxin. J Clin Microbiol 20:59-64

32. Kuhn M, Adermann K, Jahne J, Forssmann WG, Rechkemmer G 1994 Segmental differences in the effect of guanylin and Escherichia coli heat-stable enterotoxin on $\mathrm{Cl}^{-}$secretion in human gut. J Physiol 479:433-440

33. Charney AN, Egnor RW, Alexander-Chacko JT, Zaharia V, Mann EA, Giannella RA 2001 Effect of E. coli heat-stable enterotoxin on colonic transport in guanylyl cyclase C receptor-deficient mice. Am J Physiol Gastrointest Liver Physiol 280:G216-G221

34. Forte LR, Eber SL, Turner JT, Freeman RH, Fok KF, Currie MG 1993 Guanylin stimulation of $\mathrm{Cl}^{-}$secretion in human intestinal T84 cells via cyclic guanosine monophosphate. J Clin Invest 91:2423-2428

35. Canani RB, Cirillo P, Buccigrossi V, De Marco G, Mallardo G, Bruzzese E, Polito G, Guarino A 2003 Nitric oxide produced by the enterocyte is involved in the cellular regulation of ion transport. Pediatr Res 54:64-68

36. Cohen MB, Guarino A, Shukla R, Giannella RA 1988 Age-related differences in receptors for Escherichia coli heat-stable enterotoxin in the small and large intestine of children. Gastroenterology 94:367-373

37. Goldstein JL, Sahi J, Bhuva M, Layden TJ, Rao MC 1994 Escherichia coli heat stable enterotoxin-mediated colonic Cl- secretion is absent in cystic fibrosis. Gastroenterology 107:950-956

38. Guarino A, Cohen MB, Giannella RA 1987 Small and large intestinal guanylate cyclase activity in children: effect of age and stimulation by Escherichia coli heat-stable enterotoxin. Pediatr Res 21:551-555 